OPEN ACCESS

Edited by:

Federico Cesano,

University of Turin, Italy

Reviewed by:

Arunas Ramanavicius, Vilnius University, Lithuania

Hubert Perrot,

UMR8235 Laboratoire Interfaces et Systèmes Electrochimiques (LISE),

France

*Correspondence:

Danilo Dini

danilo.dini@uniroma1.it

Specialty section:

This article was submitted to

Inorganic Chemistry,

a section of the journal

Frontiers in Chemistry

Received: 18 May 2021

Accepted: 22 July 2021

Published: 19 August 2021

Citation:

Dini D, Salatelli E and Decker F (2021)

EQCM Analysis of the Insertion

Phenomena in a n-Doped Poly-Alkyl-

Terthiophene With Regioregular

Pattern of Substitution.

Front. Chem. 9:711426.

doi: 10.3389/fchem.2021.711426

\section{EQCM Analysis of the Insertion Phenomena in a $n$-Doped Poly-Alkyl-Terthiophene With Regioregular Pattern of Substitution}

\author{
Danilo Dini ${ }^{1 *}$, Elisabetta Salatelli ${ }^{2}$ and Franco Decker ${ }^{1}$ \\ ${ }^{1}$ Department of Chemistry, University of Rome "La Sapienza", Rome, Italy, 2Department of Industrial Chemistry "Toso Montanari", \\ University of Bologna, Bologna, Italy
}

In the present work, we have undertaken the study of the $n$-doping process in poly-3,3"didodecyl-2,2' $: 5^{\prime}, 2^{\prime \prime}$-terthiophene (poly-33"'-DDTT) employing the electrochemical quartz crystal microbalance (EQCM). The present study aims at understanding how cathodic charge in $n$-doped poly-33"-DDTT is compensated. For this purpose, the in situ analysis of the variations of the polymeric mass has been considered. Poly-33"-DDTT was obtained as a thin coating onto a metallic substrate via the anodic coupling of the corresponding

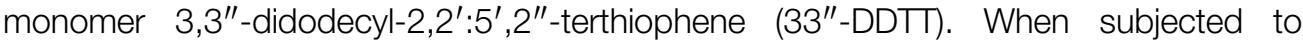
electrochemical $n$-doping in the polarization interval $-2.5 \leq E_{\text {appl }} \leq 0 \mathrm{~V} v \mathrm{vs}$. $\mathrm{Ag} / \mathrm{Ag}^{+}$, the films of poly-33"-DDTT varied their mass according to a mechanism of cations insertion during $n$-doping and cations extraction during polymer neutralization. In fact, the electrochemical doping of polythiophenes requires the accompanying exchange of charged species to maintain the electroneutrality within the structure of the polymer in all states of polarization. At the end of a full electrochemical cycle (consisting of the $n$-doping and the successive neutralization of poly-33"-DDTT), the polymer retains a fraction of the mass acquired during $n$-doping, thus manifesting the phenomena of mass trapping. The combined analysis of electrochemical and microgravimetric data suggests that poly-33"-DDTT in the $n$-doped state undergoes (or electrocatalyzes) uncontrolled electrochemical reactions that are not accompanied by mass variations.

\footnotetext{
Keywords: conducting polymers, regioregular polythiophene, EQCM gravimetry, n-doping, electrochemical insertion
}

\section{INTRODUCTION}

Polythiophenes (PTs) are heterocyclic polymers with an extended area of electronic delocalization (Brédas et al., 2016), which possess high chemical and physical stability (Tourillon and Skotheim, 1986). By virtue of these properties, PTs are successfully employed as active materials in many advanced applications, e.g., photovoltaic cells (Marinelli et al., 2020a; Lanzi et al., 2020; Lanzi et al., 2018; Kippelen et al., 2016), sensors (Wang et al., 2017; Chan et al., 2017a; Guiseppi-Elie et al., 1998), and electroluminescent devices (Kerfoot et al., 2020; Kameta and Shimizu, 2020; Menke et al., 2016), among others (Lodola et al., 2019; Barbarella and Di Maria, 2015; Di Maria et al., 2014; Zessin et al., 2017; Carreon et al., 2014; Chaudhary et al., 2019; da Rocha Rodrigues et al., 2020; Jung et al., 1998; Angiolini et al., 2013; Sheehan et al., 2015; Zheng et al., 2016). PTs are also studied in the ambits of 

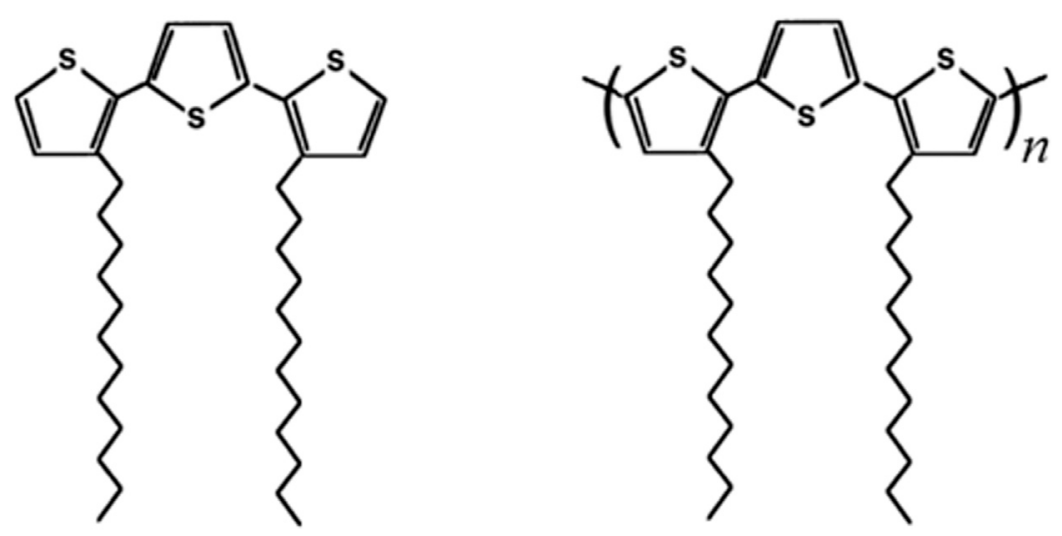

FIGURE 1 | Sketches of 3,3"-DDTT (monomer on the left) and poly-3,3"-DDTT (polymer on the right). The monomer 3,3"-DDTT has been employed as a precursor for the electrochemical deposition of the corresponding polymer poly-3,3"-DDT.

nonlinear optics (Hartmann et al., 2001; Jahja and Bubeck, 2010; Persoons et al., 2016), photonics (Portone et al., 2019; Cornil et al., 1999), and organic electronics (Hsieh et al., 2016; Kanibolotsky et al., 2015; Lee et al., 2016) due to the high polarizability and mobility of the $\pi$-electrons present in large concentrations (Xie et al., 2016; Kossmehl and Skotheim, 1986). PTs received great attention among academic and industrial researchers due to the versatility of their synthetic chemistry (Marsitzky et al., 1999; Diaz et al., 1986; Roncali et al., 1998; Alhalasah and Holze, 2005; Roncali, 1997), the diversity of PTs applications (Ellis and Skotheim, 1986; McGehee et al., 1999), and the ability to switch their chemical-physical properties reversibly in response to stimuli of very different nature (electrochemical, electrical, optical, magnetic, thermal, chemical, or biological) (Inganäs, 2010; Otero, 2016). Among various typologies of PTs (Roncali, 1992), there is a general interest in those systems that are derived by the starting monomers constituted by regioregular oligothiophenes (Glenis et al., 1995; Ponnapati et al., 2010; Angiolini et al., 2015). Besides the well-established switching properties that are common in all PTs (Pernites et al., 2011; Xu et al., 2015; Strover et al., 2012; Strover et al., 2017; Friebe et al., 2013; Moreira et al., 2020; Hazra et al., 2020; Chan et al., 2017b; MacDiarmid et al., 1985), this is because the resulting polymers can also display a strong optical activity by virtue of their uncommon chiral properties (Marinelli et al., 2020b; Salatelli et al., 2010). In particular, in this work, we have considered the electrochemical synthesis (MacDiarmid et al., 1985; Biallozor and Kupniewska, 2005; Scrosati, 1988) of the polymer obtained from the anodic coupling of the regioregular monomer 3,3"-didodecyl-2,2 $: 5^{\prime}, 2^{\prime \prime}$-terthiophene (33"-DDTT; Figure 1, left sketch) (Dini et al., 1998; Dini et al., 1999a; Dini et al., 1999b; Tarola et al., 1999; Tsionsky et al., 1998; Dini et al., 2000) for the analysis of the process of electrochemical n-doping (or, equivalently, the electrochemical reduction). The resulting polymer poly-3,3"-didodecyl-2,2': $5^{\prime}, 2^{\prime \prime}$-terthiophene (poly-33"-DDTT; Figure 1, right sketch) is obtained as a thin film on a supporting metallic substrate when the polymerization of $33^{\prime \prime}$-DDTT monomer (Figure 1, left sketch) is conducted electrochemically through a potentiodynamic route. In this context, we have analyzed the mass variations of poly-33"-DDTT during electrochemical n-doping employing the electrochemical quartz crystal microbalance (EQCM) (Naoi et al., 1991; Buttry and Ward, 1992; Dini et al., 2021), i.e., a non-invasive tool that detects in situ the mass changes accompanying a solid-state electrochemical process (Schiavon et al., 1994; Ward and Meyers, 2000). EQCM also represents a sophisticated tool at the basis of those advanced approaches (Gao et al., 2017; Lé et al., 2019) that intend to discern the directions of the fluxes through the electrode/electrolyte interface for the different species involved in an electrochemically driven redox process at an electronically conducting polymer (Arbizzani et al., 1999). In some examples of particular complexity, some researchers have coupled EQCM with AC-electrogravimetry (Lé et al., 2019) and with electroacoustic techniques (Gao et al., 2017) to elucidate the role of anions, cations, and solvent in the charge compensation mechanisms of PEDOT nanowires and dodecylsulfate-doped polypyrrole taking into account the modification of the viscoelastic properties of the polymers undergoing continuous electrochemical cycling. Moreover, EQCM has demonstrated its usefulness in the evaluation of the dynamics of polymerization in the case of the potential pulse sequence-based electrochemical deposition of polypyrrole (Plausinaitis et al., 2015) and the verification of spontaneous adsorption phenomena consisting in the formation of adlayers of pyrrole on metallic substrates prior to any sequence of electrical polarization (Plausinaitis et al., 2017).

Since the electrochemical doping of conducting polymers like PTs is a solid-state reaction (Scrosati and Bruce, 1994) that necessitates the exchange of charged species for the maintenance of electroneutrality in the doped polymer, the use of the EQCM tool appears appropriate in this context (Doblhofer et al., 1998). EQCM analyses of PTs $n$-doping are not frequently reported in the literature (Borjas and Buttry, 1991; Berlin et al., 2004; Casalbore-Miceli et al., 2007; Dini et al., 2021) because the electrochemical reduction of PTs is complicated by the reactivity of PTs in the reduced state in ambient conditions and by the selectivity of reduced PTs towards the charge-compensating 


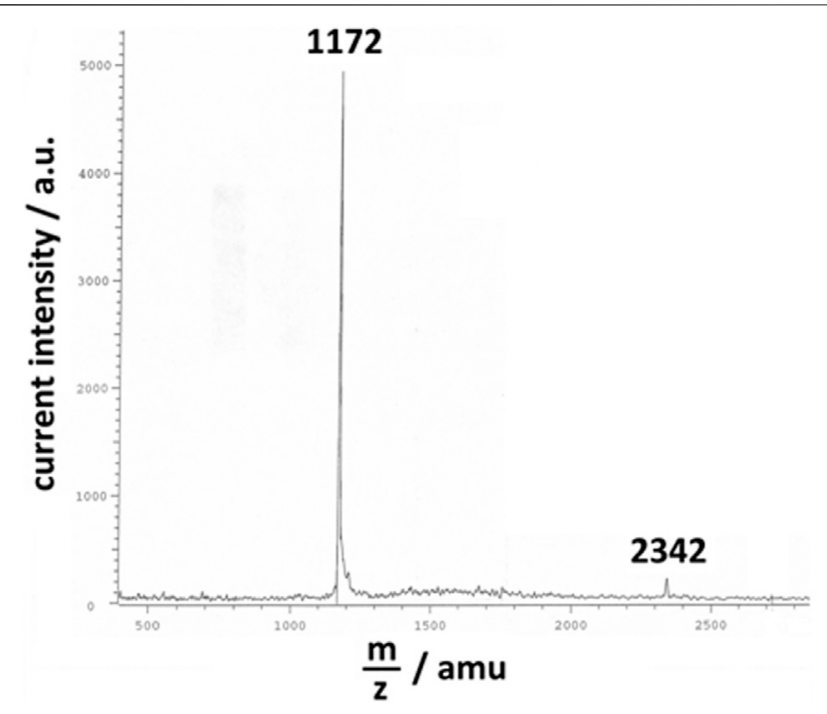

FIGURE 2 | MALDI-TOF spectrum of the fraction of poly-3,3"-DDTT electrodeposit, which is soluble in $\mathrm{CHCl}_{3}$. The most intense peaks were detected at 1,172 and 2,342 amu. These values indicate that the $\mathrm{CHCl}_{3}$ soluble fraction of poly-3,3"-DDTT was mainly constituted by the dimer and the tetramer of the starting monomer 3,3"-DDTT (with molecular mass 585). In the MALDI-TOF spectrum, the peak associated with the largest mass (not shown) was detected at $m / z=4,099$, i.e., for the oligomer constituted by seven units of $3,3^{\prime \prime}$-DDTT.

cations to be incorporated (Mastragostino and Soddu, 1990; Zotti and Schiavon, 1994; Zotti et al., 1995; Levi et al., 2000). Through this work, we aim to understand the mechanisms of charge compensation/electron injection that underlie the $n$-doping of poly-33"-DDTT when the process is conducted in a controlled atmosphere taking advantage of the analytical approach we adopted previously (Naoi et al., 1991).

\section{EXPERIMENTAL SECTION}

\section{Electrochemical Polymerization}

For the electrochemical deposition of the corresponding polymer, a solution of electrolysis containing the starting monomer $3,3^{\prime \prime}$ DDTT was prepared. The procedures of electrosynthesis used for the realization of the present paper are very similar to the ones reported in (Naoi et al., 1991), the sole difference being the employment of the isomer $3,3^{\prime \prime}$-DDTT instead of $3^{\prime}, 4^{\prime}$-DDTT. In fact, the solution was obtained by dissolution of the monomer $3,3^{\prime \prime}$-DDTT with variable concentrations (concentration range: $0.3 \leq c \leq 5 \mathrm{mM}$ ) in a mixture of $\mathrm{CH}_{3} \mathrm{CN}$ (acetonitrile, $\mathrm{ACN}$, from Sigma-Aldrich, HPLC gradient grade, $\geq 99.9 \%$ ) and $\mathrm{C}_{6} \mathrm{H}_{5} \mathrm{CN}$ (benzonitrile, BN, from Sigma-Aldrich, Reagent Plus grade, 99\%). The $\mathrm{ACN} / \mathrm{BN}$ mixture had the volume ratio of $\mathrm{ACN} / \mathrm{BN}=4: 1$ (Dini et al., 1999b; Tarola et al., 1999). ACN and BN were used without any further treatment of purification as in our analogous previous work (Dini et al., 2021). In the solution of electrolysis, the salt $\left(n-\mathrm{C}_{4} \mathrm{H}_{9}\right)_{4} \mathrm{NClO}_{4}$ (tetrabutylammonium perchlorate, TBAP, from Sigma-Aldrich/Supelco with purity $\geq 99.0 \%$ ) was added as supporting electrolyte (SE) at the concentration $c=0.1 \mathrm{M}$. TBAP was dried under vacuum at $70^{\circ} \mathrm{C}$ before its dissolution in the solution of electrolysis. Prior to the electrochemical deposition of poly-3,3"-DDTT, the solution of electrolysis (containing the monomer and SE) was purged with $\mathrm{N}_{2}$ (nitrogen from Air Liquide) for $1 \mathrm{~h}$ at room temperature. The electrodeposition of poly-3,3"-DDTT was conducted at room temperature in a three-electrode cell with $\mathrm{Ag} / \mathrm{Ag}^{+}$as the reference electrode $(\mathrm{RE})\left[c\left(\mathrm{AgNO}_{3}\right)=0.01 \mathrm{M}\right.$ in $\left.\mathrm{ACN}\right]$ and a $\mathrm{Pt}$ wire as the counterelectrode (CE). Pt and Ag wires (diameter, $\varnothing=1 \mathrm{~mm}$ ) were purchased from Goodfellow, while $\mathrm{AgNO}_{3}$ at the highest purity grade (99.9999\%) was obtained from Sigma-Aldrich. The WE of the cell constituted the substrate onto which poly-33"DDTT was deposited as a thin layer (thickness $l<10 \mu \mathrm{m}$ ) (Tsionsky et al., 1998). The choice of the electrode-substrate is conditioned by the type of analysis the polymer film had to pass successively (Dini et al., 1999b; Dini et al., 2021). For the preparation of the polymer sample to be analyzed with the EQCM, cell configuration reported by Naoi et al., 1991, and Persoons et al., 2016, was adopted with an Au-coated AT-cut quartz disk as WE (area $0.35 \mathrm{~cm}^{2}$; frequency of resonance $6 \mathrm{MHz}$ ) (Dini et al., 1998; Dini et al., 1999a). For the analysis of the UVVis properties of poly-3,3"-DDTT, the polymer was deposited onto a conductive substrate made of transparent tin-doped indium oxide (ITO)-covered glass (ITO, from Optics Balzers) with an area of $3 \times 1 \mathrm{~cm}^{2}$. All polymeric samples were deposited electrochemically in the potentiodynamic mode, the WE being polarized within the applied potential range $0 \leq E_{\text {appl }}<1 \mathrm{~V} v s$. Ag/ $\mathrm{Ag}^{+}$. The potentiodynamic deposition of poly-3,3"-DDTT was conducted at variable scan rates (scan rate range $50 \leq$ $v \leq 200 \mathrm{mV} \mathrm{s}^{-1}$ ) with supernatant $\mathrm{N}_{2}$ in the headspace of the cell. In the chosen range of applied potential, the monomer 3,3" DDTT and its derived oligomers could be oxidized in order to start the desired process of oxidative polymerization (Tsionsky et al., 1998; Dini et al., 2021). After deposition, the

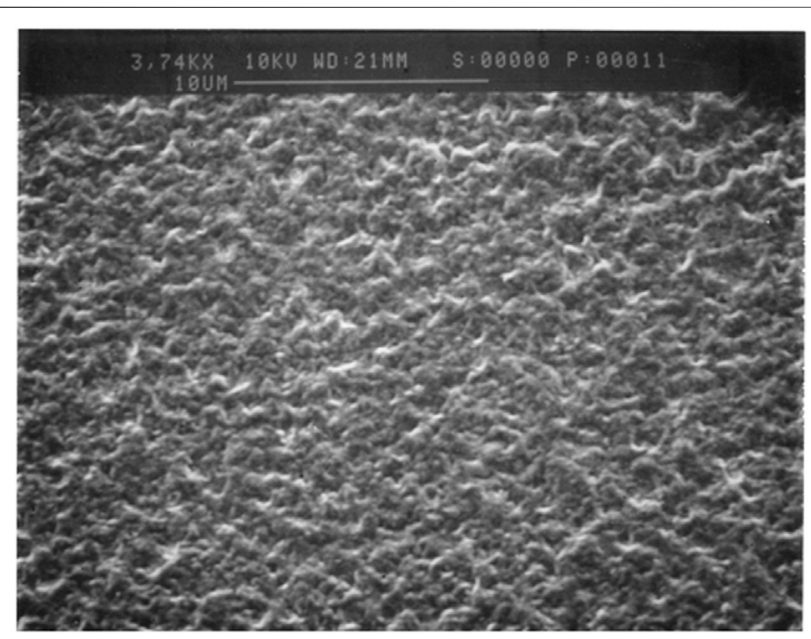

FIGURE 3 | SEM picture of poly-3,3"-DDTT in the neutral state. Similar to the treatment of the electrodeposit described in (Naoi et al., 1991), the polymer was rinsed with $\mathrm{CHCl}_{3}$ and successively dried with a stream of $\mathrm{N}_{2}$. 


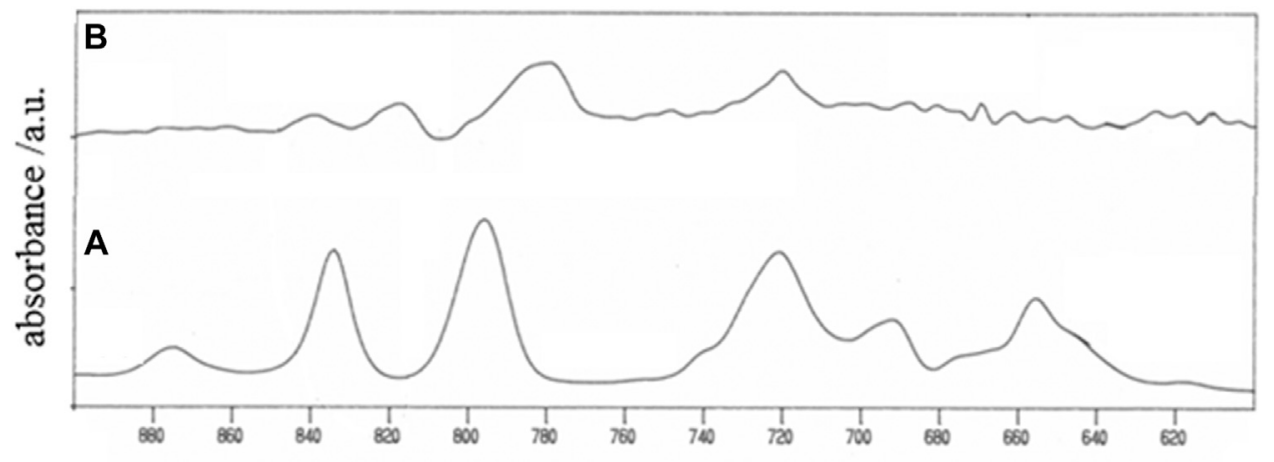

wavenumber $/ \mathrm{cm}^{-1}$

FIGURE 4 | IR spectra of (A) monomer 3,3"-didodecyl-2,2':5',2"-terthiophene and (B) the corresponding electropolymerized product poly-3,3"-DDTT (wavenumber range 600-900 $\mathrm{cm}^{-1}$ ). The polymer was neutral as obtained at the end of the voltammetric experiment of Figure 5 (vide infra). The charge of polymer deposition was $25 \mathrm{mC}$. Spectra were recorded in the reflectance mode.

polymer-covered WE was rinsed with $\mathrm{CHCl}_{3}$ (chloroform from Sigma-Aldrich with purity $\geq 99.5 \%$ ) to remove the polymeric fraction constituted by the shorter chains. The electrodeposit of poly-3,3"-DDTT was not peeled off from the substrate as reported in (Naoi et al., 1991) and remained on the substrate as coating of the WE for the successive experiments of electrochemical $n$-doping. The $\mathrm{CHCl}_{3}$-soluble fraction of the electrodeposit contained chains with a maximum degree of polymerization, $n=7$ (Figure 2), as verified with MALDITOF mass spectrometer (instrument from Bruker). This led us to assume that the chains of poly-3,3"-DDTT with $n \geq 8$, i.e., the fraction insoluble in $\mathrm{CHCl}_{3}$, constituted the actual deposit on the WE after its rinsing with $\mathrm{CHCl}_{3}$. Before any treatment of electrochemical $n$-doping, the deposit containing the fraction of poly-3,3"-DDTT insoluble in $\mathrm{CHCl}_{3}$ was dried under vacuum for $3 \mathrm{~h}$ at room temperature and successively kept in a glovebox similar to the procedure reported in (Naoi et al., 1991). The surface morphology of the resulting polymeric sample (Figure 3) was visualized with a scanning electron microscope (SEM), a Cambridge 100 instrument with a resolution of $10 \mathrm{~nm}$ when the substrate of polymerization was ITO. The latter was chosen because of its flatness (Dini et al., 2021). The electrochemical polymerization of $3,3^{\prime \prime}$-DDTT was driven by a potentiostat/ galvanostat PAR EG\&G (mod. 362). The potentiostat was connected to a Hewlett-Packard computer through an IEEE488 GPIB interface similar to what has been reported in (Naoi et al., 1991). Data were acquired and stored in a PC using a LabVIEW Program from National Instruments Corporation as previously reported in (Naoi et al., 1991) and references therein.

The occurrence of polymerization was verified via IR spectroscopy by comparing the IR profiles of the starting monomer and the electrodeposit (Figure 4). The IR spectra were recorded in the reflectance mode with a Perkin-Elmer System 2000 FTIR employing ITO-coated glass as supporting substrate for both monomer and polymer (Dini et al., 2000). The disappearance of the bands in the range $620-705 \mathrm{~cm}^{-1}$ and the attenuation and the shifts of the bands in the range $770-890 \mathrm{~cm}^{-1}$ in passing from the monomer to the electrodeposit (Figure 4) are consistent with the occurrence of polymerization during the potentiodynamic oxidation of 3,3"-DDTT (Horak et al., 1966; Hotta et al., 1984; Akimoto et al., 1986; Furukawa et al., 1987).

\section{Electrochemical $\mathbf{n}$-Doping}

Similar to what has been reported in (Naoi et al., 1991), the electrochemical $n$-doping of poly-3,3"-DDTT was conducted potentiodynamically within the applied potential range $-2.5 \leq$ $E_{\text {appl }} \leq-0.5 \mathrm{~V} v \boldsymbol{s}$. $\mathrm{Ag} / \mathrm{Ag}^{+}$, using the same electrochemical experimental apparatus already used for the polymerization. The electrolytic solution of polymer doping was a monomerfree 3,3"-DDTT, and it was composed of 0.1 M TBAP in ACN as in the case of the analogous experiments reported in (Naoi et al., 1991). In the $\mathrm{n}$-doping experiments, supernatant $\mathrm{N}_{2}$ was flowing in a laminar mode inside the headspace of the cell. In all experiments of polymer $n$-doping, the configuration of the electrochemical cell was a poly-3,3"-DDTT-coated substrate as $\mathrm{WE}$ and a Pt wire as $\mathrm{CE}$, while the RE was based on the redox couple $\mathrm{Ag} / \mathrm{Ag}^{+}(0.34 \mathrm{~V}$ vs. SCE), similar to what has been reported in (Naoi et al., 1991).

\section{EQCM Analysis}

Similar to what has been reported in (Naoi et al., 1991), EQCM was coupled to a homemade oscillator circuit and the oscillation was monitored with a frequency counter from Hewlett-Packard (Model 5316B) (Schiavon et al., 1994). The EQCM was constituted by an Au-coated AT-cut quartz disk as a working electrode with an area of $0.35 \mathrm{~cm}^{2}$ and a resonance frequency of $6 \mathrm{MHz}$ (Dini et al., 1998; Dini et al., 1999a). The gravimetric sensitivity (corresponding to the conversion factor of the EQCM) was $\Delta \mathrm{m} / \Delta v=1.09 \mathrm{ng} \mathrm{Hz}^{-1}$ from the calibration experiment of $\mathrm{Ag}$ deposition (vide infra), and the Sauerbrey equation (Sauerbrey, 1959) was as follows:

$$
\frac{\Delta f}{f}=-\frac{\Delta l}{l}=-\frac{\Delta m_{\text {film }}}{\rho_{\text {film }} A_{\text {sub }} l},
$$


where $\Delta f$ is the vibration frequency variation of the quartz crystal (with characteristic resonance frequency $f$ ) caused by the deposition of an extra layer of thickness $\Delta l$ over a layer with initial thickness $l$. In EQCM experiments, the material constituting the extra layer with thickness $\Delta l$ does not generally correspond with the material constituting the starting layer with thickness $l$, i.e., the Au-coated quartz. Equation 1 shows that for the resonant crystal, the relative change in $f$ can be correlated with the mass $\Delta m_{\text {film }}$ of the extra deposited layer of poly-33"-DDTT having the thickness $\Delta l$ and the density $\rho_{\text {film }}$ to the area of the Au-coated quartz substrate $\left(A_{\text {sub }}\right)$ provided that the extra layer of the polymeric deposit has the same area of the resonant quartz crystal (absence of border effects) and can be mechanically considered as an extension of the Au-coated quartz substrate (Buttry and Ward, 1992). For the EQCM characterization of poly-33"-DDTT electrochemical $n$-doping reported here, the use of Eq. 1 was justified by the fact that the resonator has a high frequency $\left(>10^{5} \mathrm{~Hz}\right)$ and the working temperature is below the glass transition temperature of the regioregular poly-alkyl-thiophene $(>320 \mathrm{~K}$ ) (Yazawa et al., 2006). Moreover, the frequency change induced by the electrodeposition of poly-33"-DDTT and its n-doping is relatively small with respect to the resonance frequency of the bare substrate. In these conditions, we assume that poly$33^{\prime \prime}$-DDTT film in the neutral and $n$-doped versions is elastic (Buttry and Ward, 1992) and vibrates coherently with the underlying quartz crystal; i.e., the latter is rigidly coupled with the polymer. It is assumed that poly-33"-DDTT (in either the neutral and $n$-doped state) has the same acoustic properties of the quartz crystal when $\Delta l<350 \mathrm{~nm}$, and it is then treatable with the Sauerbrey equation (Sauerbrey, 1959) in the whole range of applied potential. For the EQCM analysis of electrochemical poly- $3,3^{\prime \prime}$-DDTT $n$-doping, the cell was polarized with a potentiostat (mod. 551 from AMEL) modulated by a programmable function generator (mod. 568 from AMEL) similar to the experimental apparatus reported in (Naoi et al., 1991) and references therein. The potential was coupled to a digital integrator (mod. 731 from AMEL) to quantify the electrical charge as in (Naoi et al., 1991). The software analyzing the charge and mass data collected by the computer was homemade (Dini et al., 2021). The software monitored the variations of the vibration frequency in the WE. Moreover, the software correlated the frequency data with WE mass changes by employing the Sauerbrey equation as reported in (Naoi et al., 1991) and references therein. The calibration of the QCM was effectuated by depositing Ag electrochemically from a $10^{-2} \mathrm{M}$ solution of $\mathrm{AgNO}_{3}$ in $\mathrm{ACN}$ when $\left(\mathrm{C}_{2} \mathrm{H}_{5}\right)_{4} \mathrm{NClO}_{4}$ (tetraethylammonium perchlorate, TEAP, Sigma-Aldrich/Supelco with purity $\geq 99.0 \%$ ) was the SE in a way similar to what has been reported in (Naoi et al., 1991). The electrode of the QCM is homogeneously covered by the electrodeposit of poly-33"-DDTT when the latter has a thickness within the range of $200-300 \mathrm{~nm}$. In the present study, the thickness of the poly-3,3"-DDTT deposit for the EQCM study ranged between 200 and $350 \mathrm{~nm}$, as verified with an optical profilometer (model WYKO NT1100) (Awais et al., 2013).

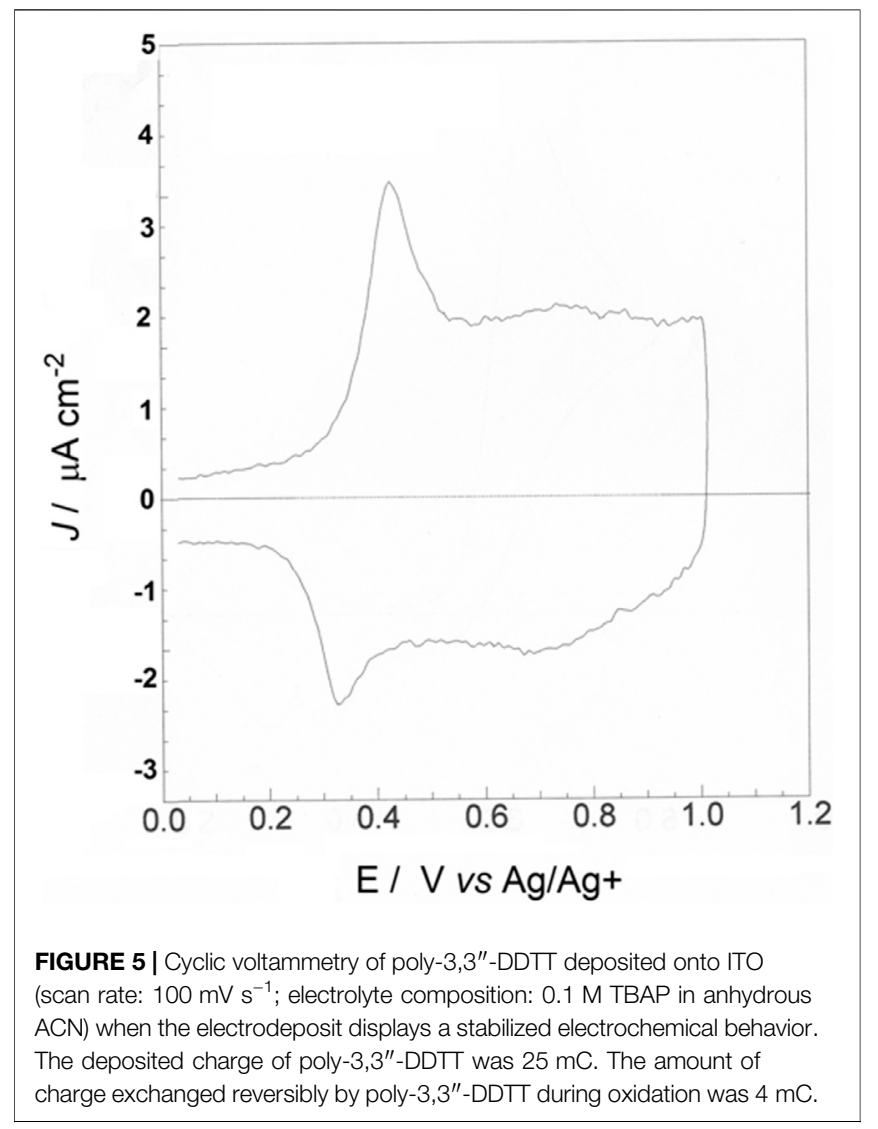

\section{UV-Vis Spectroscopy}

The UV-visible absorption spectra of poly-3,3"-DDTT were taken with the experimental apparatus described in (Naoi et al., 1991). This consisted of a Perkin-Elmer spectrometer (mod. Lambda 15) or a diode-array spectrophotometer from HP (mod. 8452A). Spectrophotometers were connected to a computer and driven by software that allowed the recording of data. The software was provided by an instrument supplier similar to what has been reported in (Naoi et al., 1991). The experimental setup is an adaptation of the one reported in refs. (Masetti et al., 1995; Dini et al., 1996), in which we make use of a gas-tight electrochemical cell (Cattarin et al., 1998). For the realization of the $\mathrm{n}$-doping experiments, the cells were assembled under a controlled atmosphere $\left(\mathrm{O}_{2}\right.$ and $\mathrm{H}_{2} \mathrm{O}$ levels lower than $10 \mathrm{ppm}$ ) in a glovebox, adopting the same procedure in (Naoi et al., 1991).

\section{RESULTS AND DISCUSSION}

After rinsing with $\mathrm{CHCl}_{3}$ and drying, the electrodeposit of poly$33^{\prime \prime}$-DDTT was electrochemically cycled in the potential interval $0.0 \leq E_{\text {appl }} \leq 1.0 \mathrm{~V}$ vs. $\mathrm{Ag} / \mathrm{Ag}^{+}$(Figure 5). The chosen range corresponds to the one in which poly-3,3"-DDTT is oxidized (Dini et al., 1999b; Tsionsky et al., 1998). The initial potentiodynamic oxidation of poly-3,3"-DDTT was conducted to check its electrochemical behavior and evaluate the 
characteristics of electronic conjugation. Poly-3,3" -DDTT layer displayed one reversible peak of oxidation at $0.40 \mathrm{~V} v s . \mathrm{Ag} / \mathrm{Ag}^{+}$, being this single peak emergent from a broad current wave of capacitive nature. (Ponder et al., 2016). The capacitive current is quasi-constant (ca. $2 \mu \mathrm{A} \mathrm{cm} ~^{-2}$ at the scan rate of $100 \mathrm{mV} \mathrm{s}^{-1}$ ) up to $1.00 \mathrm{~V} v s . \mathrm{Ag} / \mathrm{Ag}^{+}$, i.e., the upper limit of applied potential for the oxidative voltammetry. The ratio capacitive current to faradic current $\left(\mathrm{I}_{\text {cap }} / \mathrm{I}_{\text {far }}\right)$ is ca. 1.6 for poly-33"-DDTT undergoing electrochemical oxidation; i.e., poly-33"-DDTT shows a capacitive contribution larger than the faradic one. Such a value of $\mathrm{I}_{\text {cap }} / \mathrm{I}_{\text {far }}$ indicates that both processes of anion intercalation (related to the initial faradic process of polymer oxidation under the anodic peaks of Figure 5) (Zotti et al., 1993) and double layer formation (related to pseudo-capacitive phenomena within the polymeric slab during redox-charge injection) (Feldberg, 1984; Scotto et al., 2019) are taking place within poly-33"-DDTT. The co-existence of these two different types of charging phenomena in poly-33"-DDTT leads us to suppose that the charge-compensating anions occupy different types of polymeric sites according to the analysis of Tanguy et al., who distinguished the sites in trapping and non-trapping depending on the depth of anion penetration during the different phases of polymer oxidation (Tanguy et al., 1987).

The current profile of poly-3,3"-DDTT during oxidation is characterized then by a single response. As a such, the voltammogram of poly-3,3"-DDTT recalls one of those polythiophenes having a distorted structure, i.e., with the thiophene rings in an initial non-coplanar conformation (Sannicolò et al., 1998). In poly-3,3"-DDTT, the lack of coplanarity for the concatenated heterocycles along the chain axis is ascribed to the steric hindrance generated by the dodecyl groups that face each other in the starting monomer 33"-DDTT (Figure 1, left sketch). Thanks to their extended length, the two long alkyl substituents (linked in the positions three of monomer terminal rings) can also induce a head-to-head interaction (Zotti and Schiavon, 1989) through the central, unsubstituted ring of thiophene. In this context, it is worth recalling that the polymer obtained from the oxidative polymerization of $3^{\prime}, 4^{\prime}$-didodecyl-2,2':5',2 $2^{\prime \prime}$-terthiophene $\left(3^{\prime}, 4^{\prime}\right.$-DDTT, an isomer of $3,3^{\prime \prime}$-DDTT) does not show the same type of voltammetric response as poly-3,3"-DDTT (Figure 5) in analogous conditions of electrochemical cycling (Dini et al., 2021). This is because the current profile of poly$3^{\prime}, 4^{\prime}$-DDTT presents two oxidation levels (Salatelli et al., 2016) $v s$. one level of poly-3,3"-DDTT (Figure 5). This finding leads us to suppose that poly- $3^{\prime}, 4^{\prime}$-DDTT possesses high structural order (at the intrachain level) and an extended length (along chain axis) on which adjacent thiophene rings have a coplanar conformation (in contrast to poly-3,3"-DDTT, vide supra). Similar to other PTs (Roncali, 1992), the single peak of oxidation of poly-3,3"-DDTT is associated with the injection of positive polarons (spin-bearing species) and positive spin-less bipolarons (Dini et al., 1999b). Such an injection occurs in concomitance with the uptake of negative ions having the function of neutralizing the excess of positive charge in the oxidized polymer (Dini et al., 2000; Soavi et al., 2000; CasalboreMiceli et al., 2007).
Under these circumstances, the process of positive polarons/ bipolarons insertion in oxidized poly- $3,3^{\prime \prime}$-DDTT provokes a structural/conformational change, consisting in the transformation of a twisted conformation (typical of a polymer in the neutral non-conductive state) into a flat conformation (the quinoid form). The quinoid form is expected to be not particularly extended in poly-3,3" given the steric hindrance of the dodecyl groups (vide supra) when poly-33"-DDTT is in the oxidized version that contains initially only polarons. The further oxidation of poly- $3,3^{\prime \prime}$-DDTT provokes the insertion of bipolarons (representing the charge carriers of poly-3,3"-DDTT in the regime of heavy oxidation), but such an electrochemical process does not induce any structural alteration of the quinoid form (Dini et al., 1999b; Dini et al., 2021; Zotti and Schiavon, 1989). Poly-3,3"-DDTT at the highest level of oxidation $\left(E_{\text {appl }}=1.00 \mathrm{~V}\right.$ vs. $\mathrm{Ag} / \mathrm{Ag}^{+}$, Figure 5) is swollen and contains the largest amount of charge-compensating anions $\left(\mathrm{ClO}_{4}{ }^{-}\right.$in the present study) (Dini et al., 1998).

It is then expected that the structure of poly-3,3"-DDTT will suffer a maximum of mechanical stress at $E_{\text {appl }}=1.00 \mathrm{~V} v s . \mathrm{Ag} /$ $\mathrm{Ag}^{+}$. (Dini and Decker, 1998). Mechanical stress is unavoidably experienced by electrochemically switched conducting polymers like poly-3,3"-DDTT undergoing cycles of oxidation/ neutralization and reduction/neutralization. This is due to the exchange of the charge-compensating ions between the polymer and the electrolyte to preserve polymer electroneutrality. Such an exchange would provoke variations of surface tension at the (deformable) polymer/electrolyte and (rigid) polymer/Au substrate interfaces to vary the charge content in poly- $3,3^{\prime \prime}$ DDTT. The main mechanical effect induced by the simultaneous uptake/release of mass and charge is supposed to consist mostly in the variation of poly-3,3"-DDTT film thickness. Thus, the relief of mechanical stress is achieved through a volume change by poly-3, $3^{\prime \prime}$-DDTT, the latter being a deformable system. It is believed that the eventual residual mechanical stress that is not attenuated by poly- $3,3^{\prime \prime}$-DDTT through its volume variation produces negligible effects on the response of the quartz resonator in the EQCM. In deformable systems like conducting polymers, the tendency of relieving efficaciously the mechanical stress originated by the insertion/addition of molecular species has rendered the use of EQCM advantageous as an analytical tool for the verification of the occurrence of molecular imprinting of uric acid (Plausinaitis et al., 2020) and caffeine (Ratautaite et al., 2015) in polypyrrole-based sensors.

In comparison to isomeric poly-3' $4^{\prime}$-DDT (Dini et al., 2021), the presence of a relatively sharp cathodic peak in the oxidative voltammogram of poly-3,3"-DDTT denotes the occurrence of a phase transition consisting in a dramatic structural modification of poly-3,3" -DDTT when the extractions of bipolarons (at $E_{\text {appl }}>$ $0.4 \mathrm{~V} v s . \mathrm{Ag} / \mathrm{Ag}+$ ) and polarons (at $E_{\mathrm{appl}}<0.4 \mathrm{~V} v s . \mathrm{Ag} / \mathrm{Ag}+$ ) take place (Berlin et al., 2004). In poly-3,3"-DDTT, the neutralization of polarons and bipolarons is concomitant with the release of $\mathrm{ClO}_{4}{ }^{-}$anions in the adopted experimental conditions. In fact, during the different stages of poly-3,3" -DDTT oxidation, $\mathrm{ClO}_{4}{ }^{-}$ anions are inserted in the electrochemically oxidized version of the polymer to compensate for its positive charge (Dini et al., $1999 b)$. The absorption spectrum of neutral poly-3,3"-DDTT 


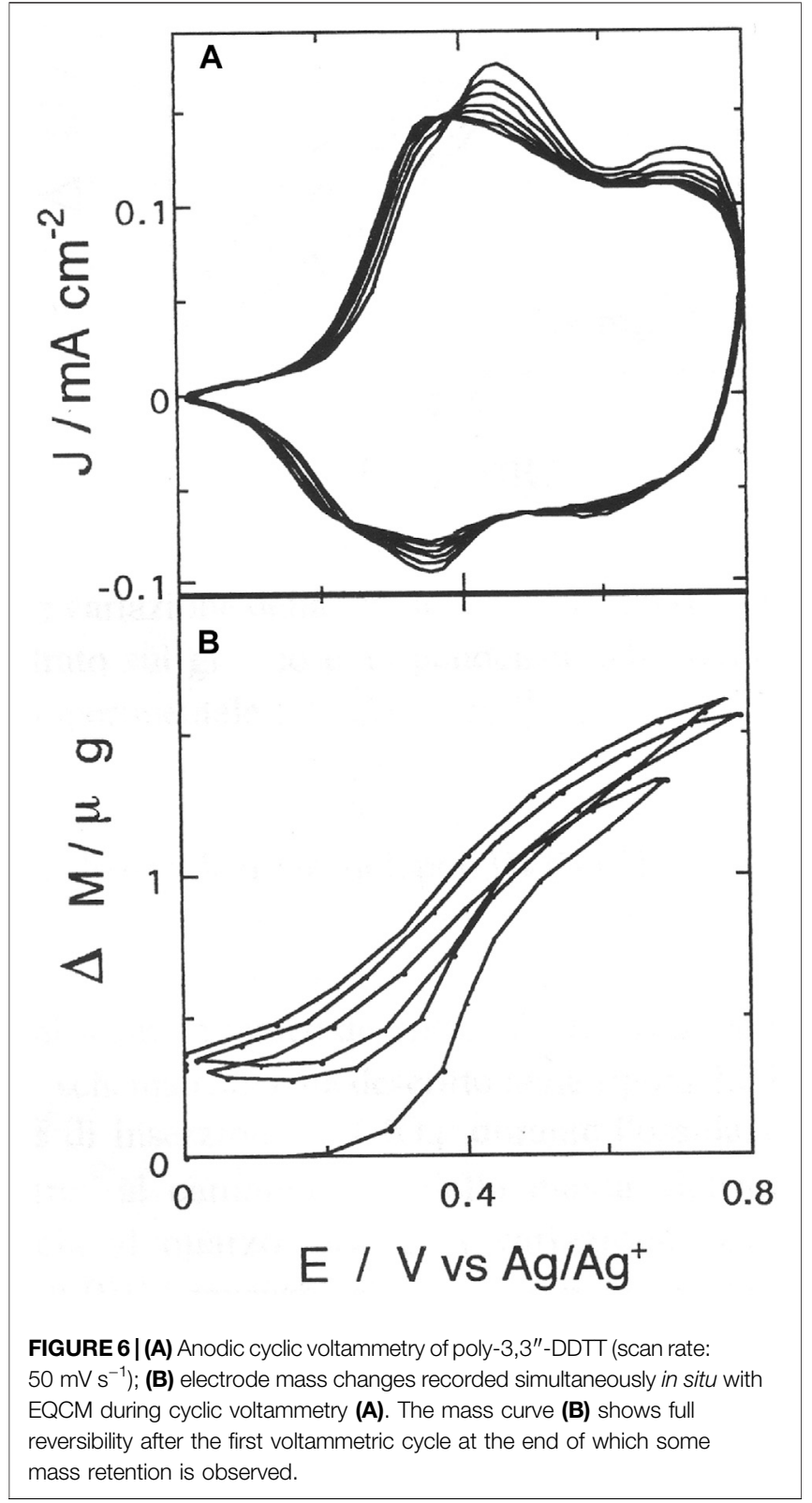

shows a broad peak with the maximum positioned at $447 \mathrm{~nm}$ (not shown). Prior to the EQCM analysis of the electrochemical $n$-doping process in poly-3,3"-DDTT, the polymer was kept at $-0.5 \mathrm{~V} v s . \mathrm{Ag} / \mathrm{Ag}+$ for $15 \mathrm{~min}$ in order to complete its electrical neutralization. The latter process completely removed residual anions from as-deposited poly-3,3"-DDTT (verified with EQCM, vide infra). In fact, the EQCM analysis of the electrochemical p-doping process in poly-33"-DDTT showed the reversible exchange of the $\mathrm{ClO}_{4}^{-}$anion during oxidative-neutralization cycles of poly-33"-DDTT after initial mass retention at the completion of the first voltammetric cycle (Figure 6). Poly$33^{\prime \prime}$-DDTT displayed a stabilized profile of the anodic cyclic voltammogram after 20-25 cycles.

Neutral poly-3,3"-DDTT was dried with a stream of $\mathrm{N}_{2}$ at room temperature. After drying, neutral poly-3,3"-DDTT was stored in a glovebox similar to the procedure reported in (Naoi et al., 1991).

\section{EQCM Characterization of Poly-33"-DDTT n-Doping}

The electrochemical reduction of poly-33"-DDTT has the potential onset at $c a .-1.7 \mathrm{~V} v s$. $\mathrm{Ag} / \mathrm{Ag}^{+}$. The profile of the voltammogram presented a quasi-reversible cathodic peak at $-2.24 \mathrm{~V}$ vs. $\mathrm{Ag} \mathrm{Ag}^{+}$(Figure 7A) when the electrolyte contained $\mathrm{TBA}^{+}$, i.e., the organic cation that is expected to play the role of charge-compensating species during $n$-doping (vide infra). The reduction voltammogram of Figure 7A has been recorded with a polymer sample thicker than the one employed in

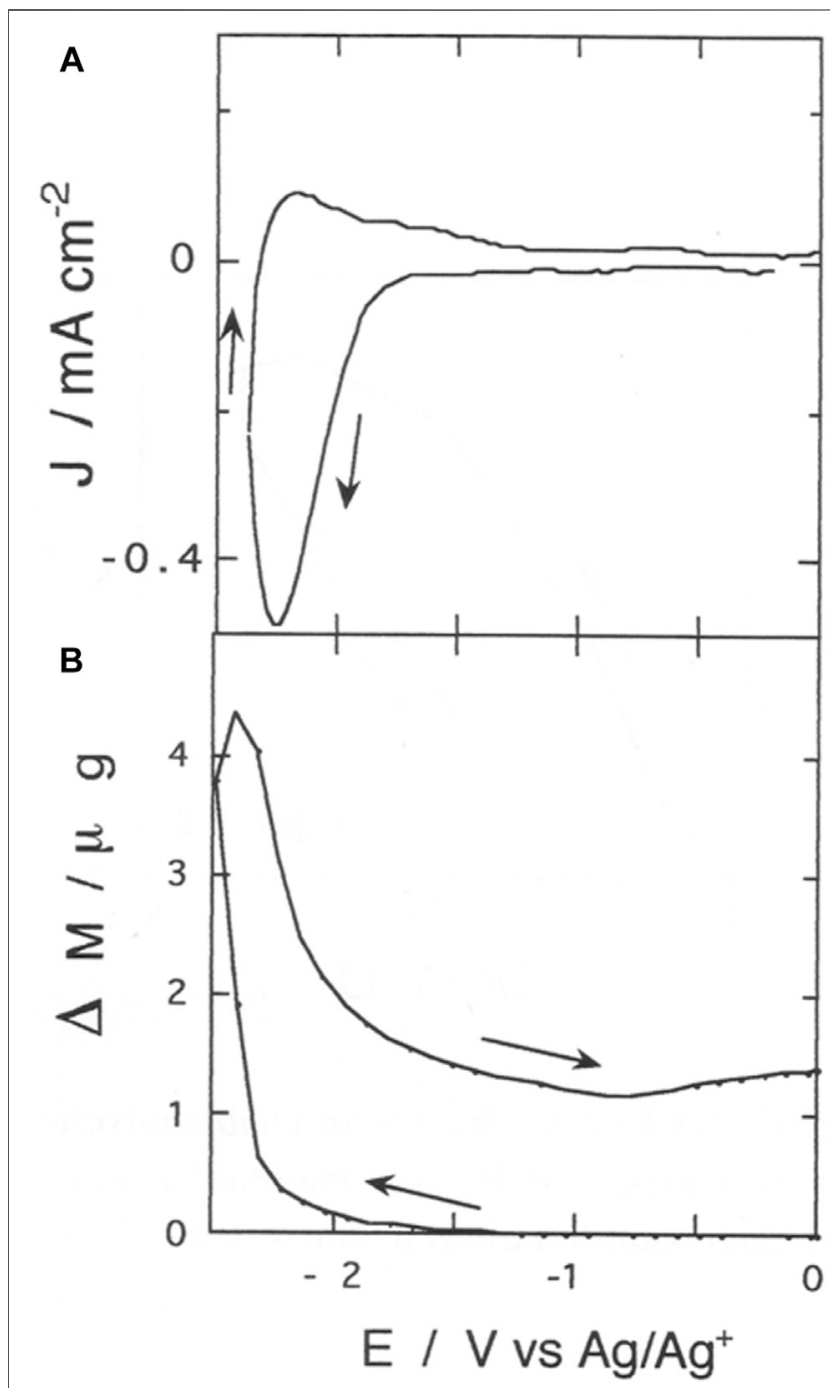

FIGURE 7 | (A) Cathodic cyclic voltammetry of poly-3,3"-DDTT (scan rate: $100 \mathrm{mV} \mathrm{s}^{-1}$ ); (B) electrode mass changes recorded simultaneously in situ with EQCM during cyclic voltammetry (A). Voltammogram (A) presents features of irreversibility, while the mass curve (B) shows phenomena of mass retention within the polymer at the completion of the applied potential cycle. 


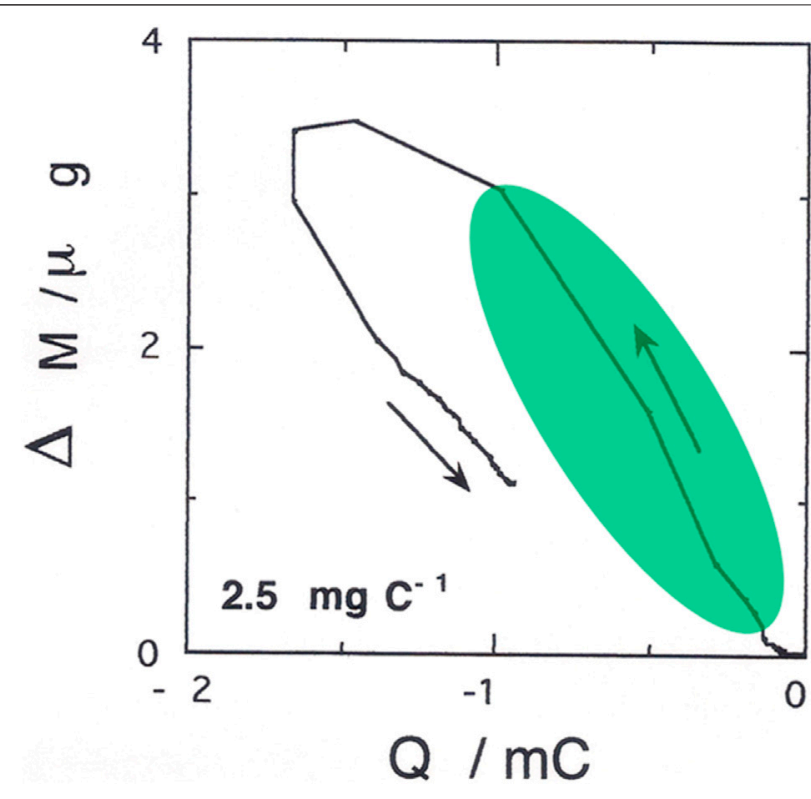

FIGURE 8 | Electrode mass variation $(\Delta m)$ with the charge $(Q)$ exchanged during the first cycle of poly-3,3"-DDTT electrochemical $n$-doping. The applied potential range was $-2.5 \leq E_{\text {appl }} \leq 0 \vee v s$. $\mathrm{Ag} / \mathrm{Ag}^{+}$similar to what has been reported in (Naoi et al., 1991). The value of $2.5 \mathrm{mg} \mathrm{C}^{-1}$ in the inset represents the slope of the linear portion evidenced in light green on the curve.

the experiment of Figure 4 ( $80 v s .25 \mathrm{mC}$ of deposited charge). In the reverse anodic scan (i.e., when the applied potential increases from -2.5 to $0 \mathrm{~V} v s . \mathrm{Ag} / \mathrm{Ag}^{+}$), the neutralization of reduced poly$33^{\prime \prime}$-DDTT occurs in a single step since it is associated with a singly-peaked current wave of considerably lower intensity in comparison to the reduction peak emerging in the direct cathodic scan (i.e., when potential decreases from 0 to $-2.5 \mathrm{~V} v s$. $\mathrm{Ag} / \mathrm{Ag}^{+}$). The important difference between the cathodic and the anodic current of poly-33"-DDTT holds for about ten cycles of potentiodynamic reduction/neutralization. Such an irreversible feature is reproducible during these first cycles. The repeatability of the profile of Figure 6 ceases after ca. 20 cycles with the progressive diminution of the current exchanged by the polymer. Upon further cycling, the evolution of the voltammogram is consistent with the degradation of poly-33"-DDTT electrochemical properties and its definitive deactivation.

The associated EQCM response (Figure 7B) is characterized by the increase of polymer mass in correspondence with the onset of the faradic process of poly-33"-DDTT $n$-doping (starting at about $-1.7 \mathrm{~V} v s . \mathrm{Ag} / \mathrm{Ag}^{+}$). Electrode mass keeps growing up to the maximum levels of polymer reduction (for $E_{\text {appl }}<-2.20 \mathrm{~V} v \mathrm{~s}$. Ag/ $\mathrm{Ag}^{+}$) and starts to decrease in the reverse anodic scan till it reaches a stationary value for $E_{\text {appl }}>-1 \mathrm{~V}$ vs. $\mathrm{Ag} / \mathrm{Ag}^{+}$ (Figure 7B). Such a value is larger than the initial one recorded before starting the electrochemical reductive cycling. Therefore, upon completion of the cycle, poly-33"-DDTT thin film retains an excess of mass ( $c a .1 .5 \mu \mathrm{g}$ in excess) with respect to the starting state. In doing so, poly-33"-DDTT exhibits an irreversible electrogravimetric behavior with the mass in excess corresponding to $\mathrm{ca}$. one-fourth of the total mass gained during $n$-doping by poly33"-DDTT. Different from the complicated electrogravimetric behavior of isomeric poly-3' $4^{\prime}$-DDTT undergoing $n$-doping (Dini et al., 2021), the cathodic polarization of poly-33"-DDTT does not induce any variation of electrode mass in the absence of a faradic process.

Polymer mass varies with the injected cathodic charge according to the profile of Figure 8. Through this experiment, we aim at identifying the species exchanged by poly- $3,3^{\prime \prime}$-DDTT during electrochemical $n$-doping. The time integration of the electrical current profile of Figure 5 allows the calculation of the consumed charge. The analysis of the $\Delta m v s$. $Q$ profile reveals that the maximum slope of the approximately linear portion (evidenced in light green in Figure 8) is $2.5^{\star} 10^{-3} \mathrm{~g} \mathrm{C}^{-1}$.

This value corresponds to the exchange of a species with a molecular mass of $241 \mathrm{amu}$ when the species bears one positive charge. The mass of the molecular cation $\mathrm{TBA}^{+}$is $242.26 \mathrm{amu}$, i.e., a value practically coincident with the one determined by the evaluation of the slope. For this reason, we assign to $\mathrm{TBA}^{+}$the role of the actual charge-compensating species for the neutralization of reduced poly-33"-DDTT. Moreover, $\mathrm{TBA}^{+}$constitutes the sole species with a positive charge that can compensate for the excess negative charge in reduced poly-33"-DDTT under the adopted experimental conditions. When $n$-doped poly-33"-DDTT undergoes neutralization, i.e., the inverse process of removal of negative charge from the polymer, a concomitant release of $\mathrm{TBA}^{+}$ cations occurs. The release of cations is relatively slow during poly-33"-DDTT neutralization with respect to the extraction of the negative charge from $n$-doped poly-33" -DDTT. This might result in a temporary excess of positive charge within a matrix of an electronically neutral polymer after completely removing the negative charge from poly-33"-DDTT. Such an excess of trapped cations would attract $\mathrm{ClO}_{4}{ }^{-}$anions, i.e., the sole mobile species with a negative charge in the adopted experimental conditions. This has no practical consequences on the polymer mass since the migration of $\mathrm{ClO}_{4}{ }^{-}$anions towards positively charged poly-33" DDTT (as a consequence of cations trapping) does not imply the uptake of these anionic species inside the polymer itself, but only the formation of a double layer-like structure at the polymer/ electrolyte interface. At the completion of the first cycle, poly$33^{\prime \prime}$-DDTT does not recover the initial value of mass. Consequently, at the start of the second cycle, poly-33"-DDTT still contains $\mathrm{TBA}^{+}$, albeit the polymer is in an electronically neutral state. The polymer is then totally deprived of electronic charge carriers (polarons or bipolarons). The second voltammetric cycle (see Supplementary Figure SA1 in the appendix) presents the same gravimetric profile of the first one, the sole difference being the position of the starting point that is upshifted in the second cycle of about $1.2 \mu \mathrm{g}$ with respect to the initial zero-mass point of the first gravimetric cycle. The (partial) release of $\mathrm{TBA}^{+}$cations occurs concomitantly with the loss of polymeric negative charge in the anodic scan (the linear part with the downward arrow), but there is a region of potential during which mass does not vary linearly with charge. The flattening of the electrogravimetric curve corresponds with potential switching that inverts the scan verse from cathodic to anodic. This finding recalls what we already observed in 
analogous conditions during the recording of the electrogravimetric curve of isomeric poly-3 $3^{\prime} 4^{\prime}$-DDTT.[66] The common electrogravimetric behavior of poly-DDTTs during their electrochemical reduction can be ascribed to parasitic reactions (either electrochemical or electrochemically induced). Possible electrochemical reactions that can be induced by the $n$-switching of poly-DDTTs are water and/or molecular oxygen reduction. In fact, both $\mathrm{H}_{2} \mathrm{O}$ and $\mathrm{O}_{2}$ can be present as impurities in the electrolyte. The parasitic reactions of $\mathrm{H}_{2} \mathrm{O}$ and $\mathrm{O}_{2}$ reduction would occur simultaneously with the electrochemical reduction of the polymer. On the other hand, $\mathrm{H}_{2} \mathrm{O}$ and $\mathrm{O}_{2}$ reductions do not lead to any variation of the electrodic mass. As reported in a previous paper dealing with the analysis of an analogous situation when the isomeric polymer poly- $3^{\prime} 4^{\prime}$-DDTT is studied (Dini et al., 2021), the $n$-doping of poly-33"-DDTT constitutes the sole faradic process that can vary the mass of the electrode, and the parasitic reaction does not. Poly- $3^{\prime} 4^{\prime}$-DDTT $n$-doping and the parasitic electrochemical reactions occur simultaneously. In this regard, we have to clarify whether the parasitic reactions are directly caused by the negative polarization of the electrode (regardless of the presence of the polymeric layer) or indirectly by the polymer when the latter is brought in the $n$-switched state, i.e., in a hypothetically conductive, electrocatalytic state. In the absence of polymer coating, the bare electrode of the EQCM does not produce any redox current in the range of applied potential where poly-33" DDTT is electrochemically reduced. Moreover, the blank experiment does not reveal any change of the mass of the bare EQCM electrode; that is, no deposition/adsorption processes are occurring during the cathodic polarization of the bare EQCM substrate. The findings of the blank experiment lead us to conclude that the parasitic reactions are of electrocatalytic nature since they require the presence of reduced poly-33"DDTT to take place. In this context, reduced poly-33"-DDTT would constitute the actual electrocatalyst of the parasitic reactions. Different from polymer $n$-doping (involving the exchange of $\mathrm{TBA}^{+}$), the parasitic reactions do not involve any exchange of species with the polymeric electrocatalyst and, consequently, do not vary the electrode mass. Therefore, the simultaneous occurrence of $n$-doping and parasitic reaction(s) will vary and diminish the slope of the $\Delta m v s$. $Q$ curve (effect of curve flattening) with respect to the exclusive occurrence of polymer $n$-doping. In the latter type of process, as a matter of fact, the consumption of charge would be accompanied in parallel by an increase of mass ( $\mathrm{TBA}^{+}$uptake) with the generation of a $\Delta m v s$. $Q$ curve having a constant, non-zero slope. Different from poly-3 $3^{\prime} 4^{\prime}$-DDTT, the occurrence of parasitic faradic reactions in poly-33"-DDTT leads to a deviation of the slope from the "correct" value of $2.5^{\star} 10^{-3} \mathrm{~g} \mathrm{C}^{-1}$ only in a limited range of applied potential (i.e., in correspondence with scan verse switching). Under these circumstances, the passage of negative charge in the range $-1.6 \leq Q \leq-1 \mathrm{mC}$ (Figure 7) cannot be associated exclusively with the exchange of $\mathrm{TBA}^{+}$cations, and a second (unknown) faradic process has to be considered. Identifying the unwanted faradic process goes beyond the scopes of the present article and will require a further analytical study entirely dedicated to this specific aspect.

\section{CONCLUSION}

Poly-3,3"-DDTT has been obtained as a thin film onto an electrically conducting substrate via the electrochemical oxidation of the corresponding terthiophenic monomer when cyclic potentiodynamic conditions were applied. During the process of poly-3,3"-DDTT $n$-doping, the EQCM detected variations in the mass of the polymer-modified electrode, which were consistent with the uptake of $\mathrm{TBA}^{+}$cation for compensating the excess of negative charge in reduced poly$3,3^{\prime \prime}$-DDTT. This is because the analysis of a $\Delta m v s$. $Q$ curve led to the determination of $2.5 \mathrm{mg} \mathrm{C}^{-1}$ as the slope of the linear portion. The value of $2.5 \mathrm{mg} \mathrm{C}^{-1}$ would correspond to the exchange of a species with a molecular mass of $241 \mathrm{amu}$, when the exchanged species carries one positive charge ( $\mathrm{TBA}^{+}$has a mass of $242 \mathrm{amu}$ ). Upon reversal of the potential, i.e., in the phase of polymer neutralization, poly-3,3"-DDTT does not recover its initial mass, thus manifesting phenomena of charge retention at the completion of a voltammetric cycle. It is supposed that the excess of positive charge retained by poly-3,3"-DDTT will recall negatively charged counterions. The latter, in turn, will not be adsorbed on the polymer surface since no increase of electrode mass could be detected during polymer neutralization in the anodic scan. Similar to what has been reported in (Naoi et al., 1991), when the applied potential approaches the lower limit of $-2.5 \mathrm{~V}$ vs. $\mathrm{Ag} / \mathrm{Ag}^{+}$, poly-3,3"-DDTT in the $n$-switched state might act as an electrocatalyst towards parasitic reactions that occur either sequentially or in parallel to poly-3,3"-DDTT $n$-doping. These uncontrolled electrochemical reactions consume charges but do not alter the electrode mass. This led us to conclude that the parasitic reactions are not solid-state electrochemical processes (Scrosati and Bruce, 1994). These unwanted and uncontrolled electrochemical reactions cause the generation of a voltammogram with irreversible features and are accompanied by the exchange of ca. $0.6 \mathrm{mC}$ of cathodic charge. Such cathodic reactions are mass transportlimited (for the presence of a current peak) and are expected to be electrocatalyzed by poly-3,3"-DDTT in the reduced n-doped state (vide supra). In conclusion, poly-3,3"-DDTT undergoing $\mathrm{n}$-doping/undoping cycles presented irreversible features in terms of electrical current and mass exchange. Different from other similar polymeric conducting systems (Dini et al., 2021), in poly-3,3"-DDTT, the kinetics of cation uptake during the cathodic scan was the same as that in the anodic scan of neutralization. As far as the applicability of poly-33"-DDTT is concerned, the analysis of the electrochemical $n$-doping process here reported demonstrates that this regioregular polyterthiophene can be exploited directly without molecular decorations as sensing element for the electrochemical detection of cations, provided that such a task is conducted by cathodically polarized poly-33"-DDTT in a non-aqueous environment. Moreover, it is expected that poly-33"-DDTT is generally prone to molecular imprinting with a variety of molecules for the creation of functional structures having high binding selectivity given the versatility and the mildness of the conditions for the electrochemical synthesis of a poly-thiophene from a terthiophenic monomer. 


\section{DATA AVAILABILITY STATEMENT}

The original contributions presented in the study are included in the article/Supplementary Material; further inquiries can be directed to the corresponding author.

\section{AUTHOR CONTRIBUTIONS}

DD contributed to the measurements realization. ES was responsible for starting monomer synthesis. FD was the research project manager. All authors have contributed equally in the writing of the manuscript.

\section{FUNDING}

The authors are indebted to Sandro Zecchin (CNR-Padua, Italy) for helpful discussions. DD acknowledges the financial

\section{REFERENCES}

Akimoto, M., Furukawa, Y., Takeuchi, H., Harada, I., Soma, Y., and Soma, M. (1986). Correlation between Vibrational Spectra and Electrical Conductivity of Polythiophene. Synth. Met. 15, 353-360. doi:10.1016/0379-6779(86)90084-6

Alhalasah, W., and Holze, R. (2005). Electrochemical Materials Science: Tailoring Intrinsically Conducting Polymers. The Example: Substituted Thiophenes. J. Solid State. Electrochem. 9, 836-844. doi:10.1007/s10008-005-0024-8

Angiolini, L., Brazzi, A., Salatelli, E., Van den Bergh, K., and Koeckelberghs, G. (2013). Polythiophene Diblock Copolymer with Different Solvent Affinities of the Side-Chain Substituents: Solvatochromism and Effect on the Electronic Conjugation. Macromol. Chem. Phys. 214, 934-942. doi:10.1002/ macp. 201300002

Angiolini, L., Cocchi, V., Guadagnini, L., Mignani, A., Salatelli, E., and Tonelli, D. (2015). Optically Active, Regioregular, Head-To-Head/tail-To-Tail Poly(3Alkyl)thiophene by Inherently Regiospecific Oxidative Synthesis from 3,3'dialkyl 2,2'-bithiophene Monomer. Synth. Met. 202, 169-176. doi:10.1016/ j.synthmet.2015.02.003

Arbizzani, C., Soavi, F., and Mastragostino, M. (1999). EQCM and Quartz Crystal Impedance Measurements for the Characterization of Thiophene-Based Conducting Polymers. MRS Proc. 600, 197-202. doi:10.1557/PROC-600-197

Awais, M., Dini, D., Don MacElroy, J. M., Halpin, Y., Vos, J. G., and Dowling, D. P. (2013). Electrochemical Characterization of NiO Electrodes Deposited via a Scalable Powder Microblasting Technique. J. Electroanalytical Chem. 689, 185-192. doi:10.1016/j.jelechem.2012.11.025

Barbarella, G., and Di Maria, F. (2015). Supramolecular Oligothiophene Microfibers Spontaneously Assembled on Surfaces or Coassembled with Proteins inside Live Cells. Acc. Chem. Res. 48, 2230-2241. doi:10.1021/ acs.accounts.5b00241

Berlin, A., Zotti, G., Zecchin, S., Schiavon, G., Vercelli, B., and Zanelli, A. (2004). New Low-Gap Polymers from 3,4-Ethylenedioxythiophene-Bis-Substituted Electron-Poor Thiophenes. The Roles of Thiophene, Donor-Acceptor Alternation, and Copolymerization in Intrinsic Conductivity. Chem. Mater. 16, 3667-3676. doi:10.1021/cm049572z

Biallozor, S., and Kupniewska, A. (2005). Conducting Polymers Electrodeposited on Active Metals. Synth. Met. 155, 443-449. doi:10.1016/ j.synthmet.2005.09.002

Borjas, R., and Buttry, D. A. (1991). EQCM Studies of Film Growth, Redox Cycling, and Charge Trapping of N-Doped and P-Doped Poly(thiophene). Chem. Mater. 3, 872-878. doi:10.1021/cm00017a024

Brédas, J.-L., Marder, S. R., and André, J.-M. (2016). “An Introduction to the Electronic Structure of $\pi$-Conjugated Molecules and Polymers, and to the Concept of supports from MIUR (Project PRIN 2017 with title "Novel Multilayered and Micro-Machined Electrode NanoArchitectures for Electrocatalytic Applications"-Prot. No. 2017YH9MRK) and from the University of Rome "La Sapienza" (Project ATENEO 2019, Prot. No. RM11916B756961CA).

\section{ACKNOWLEDGMENTS}

The authors are indebted to Dr. Sandro Zecchin (CNR-Padua, Italy) for helpful discussions.

\section{SUPPLEMENTARY MATERIAL}

The Supplementary Material for this article can be found online at: https://www.frontiersin.org/articles/10.3389/fchem.2021.711426/ full\#supplementary-material

Electronic Bands," in The WSPC Reference on Organic Electronics: ORGANIC SEMICONDUCTORS, 1: Basic Concepts. Editors J. L. Bredas and S. R. Marder (Singapore: World Scientific), 1-18. doi:10.1142/9789813148598_0001

Buttry, D. A., and Ward, M. D. (1992). Measurement of Interfacial Processes at Electrode Surfaces with the Electrochemical Quartz crystal Microbalance. Chem. Rev. 92, 1355-1379. doi:10.1021/cr00014a006

Carreon, A. C., Santos, W. L., Matson, J. B., and So, R. C. (2014). Cationic Polythiophenes as Responsive DNA-Binding Polymers. Polym. Chem. 5, 314-317. doi:10.1039/c3py01069d

Casalbore-Miceli, G., Camaioni, N., Geri, A., Ridolfi, G., Zanelli, A., Gallazzi, M. C. et al. (2007). "Solid State Charge Trapping": Examples of Polymer Systems Showing Memory Effect. J. Electroanalytical Chem. 603, 227-234. doi:10.1016/ j.jelechem.2007.02.007

Cattarin, S., Decker, F., and Dini, D. (1998). Anodic Silicon Dissolution in Acidic Fluoride Electrolyte. A Probe Beam Deflection Investigation. J. Phys. Chem. B 102, 4779-4784. doi:10.1021/jp980896i

Chan, E. W. C., Baek, P., De la Rosa, V. R., Barker, D., Hoogenboom, R., and Travas-Sejdic, J. (2017). Thermoresponsive Laterally-Branched Polythiophene Phenylene Derivative as Water-Soluble Temperature Sensor. Polym. Chem. 8, 4352-4358. doi:10.1039/c7py00919d

Chan, E. W. C., Baek, P., De la Rosa, V. R., Barker, D., Hoogenboom, R., and Travas-Sejdic, J. (2017). Thermoresponsive Laterally-Branched Polythiophene Phenylene Derivative as Water-Soluble Temperature Sensor. Polym. Chem. 8, 4352-4358. doi:10.1039/c7py00919d

Chaudhary, A., Pathak, D. K., Tanwar, M., Yogi, P., Sagdeo, P. R., and Kumar, R. (2019). Polythiophene-PCBM-Based All-Organic Electrochromic Device: Fast and Flexible. ACS Appl. Electron. Mater. 1, 58-63. doi:10.1021/acsaelm.8b00012

Cornil, J., Beljonne, D., Parente, V., Lazzaroni, R., and Bredas, J. L. (1999). "Geometric and Electronic Structure and Optical Response of Oligo- and Polythiophenes: Relation to Their Use in Electro-Optic and Photonic Devices," in Handbook of Oligo- and Polythiophenes. Editor D. Fichou (Weinheim: Wiley), 317-360.

da Rocha Rodrigues, R., da Silva, R. L. C. G., Caseli, L., and Péres, L. O. (2020). Conjugated Polymers as Langmuir and Langmuir-Blodgett Films: Challenges and Applications in Nanostructured Devices. Adv. Colloid Interf. Sci. 285, 102277. doi:10.1016/j.cis.2020.102277

Di Maria, F., Palamà, I. E., Baroncini, M., Barbieri, A., Bongini, A., Bizzarri, R., et al. (2014). Live Cell Cytoplasm Staining and Selective Labeling of Intracellular Proteins by Non-toxic Cell-Permeant Thiophene Fluorophores. Org. Biomol. Chem. 12, 1603-1610. doi:10.1039/C3OB41982G

Diaz, A. F., and Bargon, J. (1986). "Electrochemical Synthesis of Conducting Polymers," in Handbook of Conducting Polymers. Editor T. Skotheim (New York: Marcel Dekker), Vol. 1, 81-115. 
Dini, D., Decker, F., Andreani, F., Salatelli, E., and Hapiot, P. (2000). A Comparative Study of Isomeric Polydialkylterthiophenes with Regular Regiochemistry of Substitution. Electrochemical Synthesis. Polymer 41, 6473-6480. doi:10.1016/S0032-3861(99)00880-0

Dini, D., Decker, F., and Masetti, E. (1996). A Comparison of the Electrochromic Properties of WO3 Films Intercalated with $\mathrm{H}+, \mathrm{Li}+$ and $\mathrm{Na}+$. J. Appl. Electrochem. 26, 647-653. doi:10.1007/BF00253464

Dini, D., and Decker, F. (1998). Stress in Thin Films of Metal Oxide Electrodes for Intercalation Reactions. Electrochimica Acta 43, 2919-2923. doi:10.1016/s00134686(98)00032-2

Dini, D., Decker, F., and Zotti, G. (1998). Electrochemical Growth of Polyalkylthiophenes. In Situ Characterization of Deposition Processes. Electrochem. Sol. St. Lett. 1, 217-219.

Dini, D., Decker, F., Zotti, G., Schiavon, G., Zecchin, S., Andreani, F., et al. (1999). Comparative Study of Isomeric Polyalkylterthiophenes with Regular Regiochemistry of Substitution: Characterization of Electrochemical Doping Process. Chem. Mater. 11, 3484-3489. doi:10.1021/cm9910310

Dini, D., Decker, F., Zotti, G., Schiavon, G., Zecchin, S., Andreani, F., et al. (1999). EQCM Characterization of Some Substituted Polyterthiophenes. Electrochimica Acta 44, 1911-1917. doi:10.1016/S0013-4686(98)00300-4

Dini, D., Salatelli, E., and Decker, F. (2021). EQCM Analysis of the Process of Electrochemical Insertion in Regioregular Alkyl-Susbtituted Polyterthiophene during N-Doping. J. Electrochem. Soc. 168, 052506. doi:10.1149/1945-7111/ ac0173

Doblhofer, K., and Rajeshwar, K. (1998). "Electrochemistry of Conducting Polymers," in Handbook of Conducting Polymers. Editors T. A. Skotheim, R. L. Elsenbaumer, and J. R. Reynolds. 2nd Ed. (New York: Marcel Dekker), 531-588.

Ellis, J. R. (1986). "Commercial Applications of Intrinsically Conducting Polymers," in Handbook of Conducting Polymers. Editor T. Skotheim (New York: Marcel Dekker), Vol. 1, 489-499.

Feldberg, S. W. (1984). Reinterpretation of Polypyrrole Electrochemistry. Consideration of Capacitive Currents in Redox Switching of Conducting Polymers. J. Am. Chem. Soc. 106, 4671-4674. doi:10.1021/ja00329a004s

Friebe, C., Jäger, M., and Schubert, U. S. (2013). Emitting Electrode Coatings with Redox-Switchable Conductivity: Incorporation of Ruthenium(ii)-2,6Di(quinolin-8-Yl)pyridine Complexes into Polythiophene by Electropolymerization. RSC Adv. 3, 11686-11690. doi:10.1039/c3ra41356j

Furukawa, Y., Akimoto, M., and Harada, I. (1987). Vibrational Key Bands and Electrical Conductivity of Polythiophene. Synth. Met. 18, 151-156. doi:10.1016/ 0379-6779(87)90870-8

Gao, W., Sel, O., and Perrot, H. (2017). Electrochemical and Viscoelastic Evolution of Dodecyl Sulfate-Doped Polypyrrole Films during Electrochemical Cycling. Electrochimica Acta 233, 262-273. doi:10.1016/j.electacta.2017.03.05110.1016/ j.electacta.2017.03.051

Glenis, S., Benz, M., LeGoff, E., Kanatzidis, M. G., DeGroot, D. C., Schindler, J. L., et al. (1995). Electrochemical Synthesis and Electronic Properties of Poly(3,4Dibutyl-a-Terthiophene). Synth. Met. 75, 213-221. doi:10.1016/0379-6779(96) 80011-7

Guiseppi-Elie, A., Wallace, G. G., and Matsue, T. (1998). "Chemical and Biological Sensors Based on Electrically Conducting Polymers," in Handbook of Conducting Polymers. Editors T. A. Skotheim, R. L. Elsenbaumer, and J. R. Reynolds. 2nd Ed. (New York: Marcel Dekker), 963-991.

Hartmann, T., Schrof, W., Belov, V., Möhwald, H., Barth, S., Van Keuren, E., et al. (2001). Charge-induced Dephasing in Thin Polythiophene Films. Phys. Rev. B 64, 235205. doi:10.1103/PhysRevB.64.235205

Hazra, S., Shit, A., Ghosh, R., Basu, K., Banerjee, A., and Nandi, A. K. (2020). Modulation of the Optoelectronic Properties of a Donor-Acceptor Conjugate between a Cationic Polythiophene and a Peptide Appended Perylene Bisimide Ampiphile. J. Mater. Chem. C 8, 3748-3757. doi:10.1039/c9tc06593h

Horak, M., Hyams, I. J., and Lippincott, E. R. (1966). The Vibrational Spectra Thiophene Derivatives: the Monohalogenothiophenes. Spectrochimica Acta 22, 1355-1363. doi:10.1016/0371-1951(66)80039-5

Hotta, S., Hosaka, T., Soga, M., and Shimotsuma, W. (1984). 13C NMR and Fourier Transform Infrared Study of Electrochemically Prepared Polythienylene Film. Synth. Met. 10, 95-99. doi:10.1016/0379-6779(84)90085-7

Hsieh, G.-W., Wu, J.-Y., Ogata, K., and Cheng, K.-Y. (2016). Dual Layer Semiconducting Nanocomposite of Silicon Nanowire and Polythiophene for
Organic-Based Field Effect Transistors. Org. Elect. 35, 158-163. doi:10.1016/ j.orgel.2016.05.020

Inganäs, O. (2010). Hybrid Electronics and Electrochemistry with Conjugated Polymers. Chem. Soc. Rev. 39, 2633-2642. doi:10.1039/B918146F

Jahja, M., and Bubeck, C. (2010). NONLINEAR OPTICAL WAVEGUIDE SPECTROSCOPY OF POLY(3-BUTYLTHIOPHENE). J. Nonlinear Optic. Phys. Mat. 19, 269-280. doi:10.1142/S0218863510005200

Jung, S.-D., Hwang, D.-H., Zyung, T., Kim, W. H., Chittibabu, K. G., and Tripathy, S. K. (1998). Temperature Dependent Photoluminescence and Electroluminescence Properties of Polythiophene with Hydrogen Bonding Side Chain. Synth. Met. 98, 107-111. doi:10.1016/S03796779(98)00161-1

Kameta, N., and Shimizu, T. (2020). Time-controllable Roll-Up Onset of Polythiophene Sheets into Nanotubes that Exhibit Circularly Polarized Luminescence. Nanoscale 12, 2999-3006. doi:10.1039/c9nr08032e

Kanibolotsky, A. L., Findlay, N. J., and Skabara, P. J. (2015). Polythiophene and Oligothiophene Systems Modified by TTF Electroactive Units for Organic Electronics. Beilstein J. Org. Chem. 11, 1749-1766. doi:10.3762/bjoc.11.191

Kerfoot, J., Svatek, S. A., Korolkov, V. V., Taniguchi, T., Watanabe, K., Antolin, E., et al. (2020). Fluorescence and Electroluminescence of J-Aggregated Polythiophene Monolayers on Hexagonal Boron Nitride. ACS Nano 14, 13886-13893. doi:10.1021/acsnano.0c06280

Kippelen, B. (2016). “'”Organic Photovoltaics: Physical Concepts behind Device Operation" in the WSPC Reference on Organic Electronics: ORGANIC SEMICONDUCTORS," in Fundamental Aspects of Materials and Applications. Editors J. L. Bredas and S. R. Marder (Singapore: World Scientific), 2, 115-157.

Kossmehl, G. A. (1986). "Semiconducting and Conducting Polymers with Aromatic and Heteroaromatic Units," in Handbook of Conducting Polymers. Editor T. Skotheim (New York: Marcel Dekker), Vol. 1, 351-403.

Lanzi, M., Salatelli, E., Giorgini, L., Marinelli, M., and Pierini, F. (2018). Effect of the Incorporation of an Ag Nanoparticle Interlayer on the Photovoltaic Performance of green Bulk Heterojunction Water-Soluble Polythiophene Solar Cells. Polymer 149, 273-285. doi:10.1016/j.polymer.2018.07.012

Lanzi, M., Salatelli, E., Marinelli, M., and Pierini, F. (2020). Effect of Photocrosslinking of D-A Thiophene Copolymers on the Performance of Single-Material Solar Cells. Macromol. Chem. Phys. 221, 1900433. doi:10.1002/macp. 201900433

Lé, T., Aradilla, D., Bidan, G., Billon, F., Debiemme-Chouvy, C., Perrot, H., et al. (2019). Charge Storage Properties of Nanostructured Poly (3,4ethylenedioxythiophene) Electrodes Revealed by Advanced Electrogravimetry. Nanomaterials 9, 962. doi:10.3390/nano9070962

Lee, W.-Y., Mei, J., and Bao, Z. (2016). "OFETs: Basic Concepts and Materials Designs," in The WSPC Reference on Organic Electronics: ORGANIC SEMICONDUCTORS, 2: Fundamental Aspects of Materials and Applications. Editors J. L. Bredas and S. R. Marder. Singapore: (World Scientific), 19-83. doi:10.1142/9789813148611_0002

Levi, M. D., Gofer, Y., Aurbach, D., Lapkowski, M., Vieil, E., and Serose, J. (2000). Simultaneous Voltammetric and In Situ Conductivity Studies of N-Doping of Polythiophene Films with Tetraalkylammonium, Alkali, and Alkaline-Earth Cations. J. Electrochem. Soc. 147, 1096-1104. doi:10.1149/1.1393319

Lodola, F., Rosti, V., Tullii, G., Desii, A., Tapella, L., Catarsi, P., et al. (2019). Conjugated Polymers Optically Regulate the Fate of Endothelial colonyforming Cells. Sci. Adv. 5, eaav4620. doi:10.1126/sciadv.aav4620

MacDiarmid, A. G., Mammone, R. J., Kaner, R. B., and Porter, L. (1985). The Concept of 'doping' of Conducting Polymers: the Role of Reduction Potentials. Phil. Trans. R. Soc. Lond. A. 314, 3-15. doi:10.1098/rsta.1985.0004

Marinelli, M., Angiolini, L., Lanzi, M., Di Maria, F., and Salatelli, E. (2020). Effect of Regioregularity and Role of Heteroatom on the Chiral Behavior of Oligo(heteroalkyl Thiophene)s. Chirality 32, 1361-1376. doi:10.1002/ chir.23282

Marinelli, M., Lanzi, M., Liscio, A., Zanelli, A., Zangoli, M., Di Maria, F., et al. (2020). Single-material Organic Solar Cells with Fully Conjugated ElectronDonor Alkoxy-Substituted Bithiophene Units and Electron-Acceptor Benzothiadiazole Moieties Alternating in the Main Chain. J. Mater. Chem. C 8, 4124-4132. doi:10.1039/D0TC00541J

Marsitzky, D., and Müllen, K. (1999). "20 Years of "Syntetic Metals"- the Role of Synthesis," in Advances in Synthetic Metals- Twenty Years of Progress in Science 
and Technology. Editors P. Bernier, S. Lefrant, and G. Bidan (Lausanne: Elsevier), 1-97. doi:10.1016/b978-044472003-0/50001-7

Masetti, E., Dini, D., and Decker, F. (1995). The Electrochromic Response of Tungsten Bronzes MxWO3 with Different Ions and Insertion Rates. Solar Energ. Mater. Solar Cell 39, 301-307. doi:10.1016/0927-0248(95)00049-6

Mastragostino, M., and Soddu, L. (1990). Electrochemical Characterization of " $\mathrm{n}$ " Doped Polyheterocyclic Conducting Polymers-I. Polybithiophene. Electrochimica Acta 35, 463-466. doi:10.1016/0013-4686(90)87029-2

McGehee, M. D., Miller, E. K., Moses, D., and Heeger, A. J. (1999). "Twenty Years of Conducting Polymers: From Fundamental Science to Applications," in Advances in Synthetic Metals- Twenty Years of Progress in Science and Technology. Editors P. Bernier, S. Lefrant, and G. Bidan (Lausanne: Elsevier), 98-205. doi:10.1016/b978-044472003-0/50002-9

Menke, S. M., Friend, R. H., and Credgington, D. (2016). "Polymer Light Emitting Diodes," in The WSPC Reference on Organic Electronics: ORGANIC SEMICONDUCTORS, 2: Fundamental Aspects of Materials and Applications. Editors J. L. Bredas and S. R. Marder (Singapore: World Scientific), 243-276. doi:10.1142/9789813148611_0007

Moreira, T., Laia, C. A. T., Zangoli, M., Antunes, M., Di Maria, F., De Monte, S., et al. (2020). Semicrystalline Polythiophene-Based Nanoparticles Deposited from Water on Flexible PET/ITO Substrates as a Sustainable Approach toward Long-Lasting Solid-State Electrochromic Devices. ACS Appl. Polym. Mater. 2, 3301-3309. doi:10.1021/acsapm.0c00440

Naoi, K., Lien, M., and Smyrl, W. H. (1991). Quartz Crystal Microbalance Study: Ionic Motion across Conducting Polymers. J. Electrochem. Soc. 138, 440-445. doi:10.1149/1.2085606

Otero, T. F. (2016). Conducting Polymers-Bioinspired Intelligent Materials and Devices. Cambridge: Royal Society of Chemistry.

Pernites, R. B., Ponnapati, R. R., and Advincula, R. C. (2011). Superhydrophobic-Superoleophilic Polythiophene Films with Tunable Wetting and Electrochromism. Adv. Mater. 23, 3207-3213. doi:10.1002/ adma.201100469

Persoons, A. (2016). "Nonlinear Optics," in The WSPC Reference on Organic Electronics: ORGANIC SEMICONDUCTORS,1: Basic Concepts. Editors J. L. Bredas and S. R. Marder (Singapore: World Scientific), 325-392. doi:10.1142/9789813148598_0010

Plausinaitis, D., Ratautaite, V., Mikoliunaite, L., Sinkevicius, L., Ramanaviciene, A., and Ramanavicius, A. (2015). Quartz Crystal Microbalance-Based Evaluation of the Electrochemical Formation of an Aggregated Polypyrrole Particle-Based Layer. Langmuir 31, 3186-3193. doi:10.1021/la504340u

Plausinaitis, D., Sinkevicius, L., Mikoliunaite, L., Plausinaitiene, V., Ramanaviciene, A., and Ramanavicius, A. (2017). Electrochemical Polypyrrole Formation from Pyrrole 'adlayer'. Phys. Chem. Chem. Phys. 19, 1029-1038. doi:10.1039/ C6CP06545G

Plausinaitis, D., Sinkevicius, L., Samukaite-Bubniene, U., Ratautaite, V., and Ramanavicius, A. (2020). Evaluation of Electrochemical Quartz crystal Microbalance Based Sensor Modified by Uric Acid-Imprinted Polypyrrole. Talanta 220, 121414. doi:10.1016/j.talanta.2020.121414

Ponder, J. F., Jr., and Reynolds, J. R. (2016). “Conducting Polymers: Redox States in Conjugated Systems," in The WSPC Reference on Organic Electronics: ORGANIC SEMICONDUCTORS, 2: Fundamental Aspects of Materials and Applications. Editors J. L. Bredas and S. R. Marder (Singapore: World Scientific), 1-18. doi:10.1142/9789813148611_0001

Ponnapati, R., Felipe, M. J., Park, J. Y., Vargas, J., and Advincula, R. (2010). Terthiophene-Jacketed Poly(benzyl Ether) Dendrimers: Sonication Synthesis, Electropolymerization, and Polythiophene Film Formation. Macromolecules 43, 10414-10421. doi:10.1021/ma1017023

Portone, A., Ganzer, L., Branchi, F., Ramos, R., Caldas, M. J., Pisignano, D., et al. (2019). Tailoring Optical Properties and Stimulated Emission in Nanostructured Polythiophene. Sci. Rep. 9, 7370. doi:10.1038/s41598-01943719-0

Ratautaite, V., Plausinaitis, D., Baleviciute, I., Mikoliunaite, L., Ramanaviciene, A., and Ramanavicius, A. (2015). Characterization of Caffeine-Imprinted Polypyrrole by a Quartz crystal Microbalance and Electrochemical Impedance Spectroscopy. Sensors Actuators B: Chem. 212, 63-71. doi:10.1016/j.snb.2015.01.109

Roncali, J. (1998). "Advances in the Molecular Design of Functional Conjuhgated Polymers," in Handbook of Conducting Polymers. Editors T. A. Skotheim,
R. L. Elsenbaumer, and J. R. Reynolds. 2nd Ed. (New York: Marcel Dekker), 311-341.

Roncali, J. (1992). Conjugated Poly(thiophenes): Synthesis, Functionalization, and Applications. Chem. Rev. 92, 711-738. doi:10.1021/cr00012a009

Roncali, J. (1997). Synthetic Principles for Bandgap Control in Linear $\pi$-Conjugated Systems. Chem. Rev. 97, 173-206. doi:10.1021/cr950257t

Salatelli, E., Angiolini, L., and Brazzi, A. (2010). Chirality Induced by Microaggregation of Regioregular Polythiophenes with Side-Chain Optically Active Substituent. Chirality 22, E74-E80. doi:10.1002/chir.20900

Salatelli, E., Benelli, T., Caretti, D., Cocchi, V., Giorgini, L., Lanzi, M., et al. (2016). Novel Porphyrin-Containing Regioregular Poly(alkylthiophene) Copolymers Tested as Polymeric Solar Cells. Polymer 97, 314-322. doi:10.1016/ j.polymer.2016.05.040

Sannicolò, F., Brenna, E., Benincori, T., Zotti, G., Zecchin, S., Schiavon, G., et al. (1998). Highly Ordered Poly(cyclopentabithiophenes) Functionalized with Crown-Ether Moieties for Lithium- and Sodium-Sensing Electrodes. Chem. Mater. 10, 2167-2176. doi:10.1021/cm980067+

Sauerbrey, G. n. (1959). Verwendung von Schwingquarzen zur Wägung dünner Schichten und zur Mikrowägung. Z. Physik 155, 206-222. doi:10.1007/ bf01337937

Schiavon, G., Zotti, G., Comisso, N., Berlin, A., and Pagani, G. (1994). Ion Exchange in the Electrochemical Switching of Polypyrroles in Acetonitrile by the Electrochemical Quartz Crystal Microbalance. Electrolyte Incorporation by Hydrogen Bonding of Anions to Pyrrole. J. Phys. Chem. 98, 4861-4864. doi:10.1021/j100069a015

Scotto, J., Marmisollé, W. A., and Posadas, D. (2019). About the Capacitive Currents in Conducting Polymers: the Case of Polyaniline. J. Solid State. Electrochem. 23, 1947-1965. doi:10.1007/s10008-019-04291-9

Scrosati, B. (1988). Electrochemical Properties of Conducting Polymers. Prog. Solid State. Chem. 18, 1-77. doi:10.1016/0079-6786(88)90007-6

Scrosati, B. (1994). "Polymer Electrodes," in Solid State Electrochemistry. Editor P. G. Bruce (New York: Cambridge University Press), 229-263. doi:10.1017/ CBO9780511524790.010

Sheehan, S., Naponiello, G., Odobel, F., Dowling, D. P., Di Carlo, A., and Dini, D. (2015). Comparison of the Photoelectrochemical Properties of RDS NiO Thin Films for P-type DSCs with Different Organic and Organometallic DyeSensitizers and Evidence of a Direct Correlation between Cell Efficiency and Charge Recombination. J. Solid State. Electrochem. 19, 975-986. doi:10.1007/ s10008-014-2703-9

Soavi, F., Arbizzani, C., and Mastragostino, M. (2000). Quartz crystal Impedance and EQCM Measurements Applied to Dithienothiophene-Based Polymers. Phys. Chem. Chem. Phys. 2, 2993-2998. doi:10.1039/b002049o

Strover, L., Roux, C., Malmström, J., Pei, Y., Williams, D. E., and Travas-Sejdic, J. (2012). Switchable Surfaces of Electroactive Polymer Brushes Grafted from Polythiophene ATRP-Macroinitiator. Synth. Met. 162, 381-390. doi:10.1016/ j.synthmet.2011.12.024

Strover, L. T., McCulloch, B., Ho, V., Segalman, R., Malmström, J., McGillivray, D. J., et al. (2017). Tuning the Optoelectronic Properties of P3EHT Block Copolymers by Surface Modification. Ijnt 14, 540-557. doi:10.1504/ IJNT.2017.082481

Tanguy, J., Mermilliod, N., and Hoclet, M. (1987). Capacitive Charge and Noncapacitive Charge in Conducting Polymer Electrodes. J. Electrochem. Soc. 134, 795-802. doi:10.1149/1.2100575

Tarola, A., Dini, D., Salatelli, E., Andreani, F., and Decker, F. (1999). Electrochemical Impedance Spectroscopy of Polyalkylterthiophenes. Electrochimica Acta 44, 4189-4193. doi:10.1016/S0013-4686(99)00133-4

Tourillon, G. (1986). "Polythiophene and its Derivatives," in Handbook of Conducting Polymers. Editor T. Skotheim (New York: Marcel Dekker), Vol. 1, 293-350.

Tsionsky, M., Bard, A. J., Dini, D., and Decker, F. (1998). Polymer Films on Electrodes. 28. Scanning Electrochemical Microscopy Study of Electron Transfer at Poly(alkylterthiophene) Films. Chem. Mater. 10, 2120-2126. doi:10.1021/cm970795h

Wang, K.-H., Hsu, W.-P., Chen, L.-H., Lin, W.-D., and Lee, Y.-L. (2017). Extensibility Effect of Poly(3-Hexylthiophene) on the Glucose Sensing Performance of Mixed Poly(3-Hexylthiophene)/octadecylamine/glucose Oxidase Langmuir-Blodgett Films. Colloids Surf. B: Biointerfaces 155, 104-110. doi:10.1016/j.colsurfb.2017.04.006 
Ward, M. D. (2000). "Microbalance, Electrochemical Quartz Crystal," in Encyclopedia of Analytical Chemistry: Applications, Theory and Instrumentation. Editor R. A. Meyers (New York: Wiley). doi:10.1002/ 9780470027318.a5307

Xie, W., Menke, S. M., Frisbie, C. D., and Holmes, R. J. (2016). "Experimental Characterization of Charge and Exciton Transport in Organic Semiconductors," in The WSPC Reference on Organic Electronics: ORGANIC SEMICONDUCTORS, 1: Basic Concepts. Editors J. L. Bredas and S. R. Marder (Singapore: World Scientific), 231-291. doi:10.1142/9789813148598_0008

Xu, L., Chen, S., Lu, X., and Lu, Q. (2015). Electrochemically Tunable Cell Adsorption on a Transparent and Adhesion-Switchable Superhydrophobic Polythiophene Film. Macromol. Rapid Commun. 36, 1205-1210. doi:10.1002/marc.201500102

Yazawa, K., Inoue, Y., Yamamoto, T., and Asakawa, N. (2006). Twist Glass Transition in Regioregulated Poly(3-Alkylthiophene). Phys. Rev. B 74, 094204. doi:10.1103/PhysRevB.74.094204

Zessin, J., Fischer, F., Heerwig, A., Kick, A., Boye, S., Stamm, M., et al. (2017). Tunable Fluorescence of a Semiconducting Polythiophene Positioned on DNA Origami. Nano Lett. 17, 5163-5170. doi:10.1021/acs.nanolett.7b02623

Zheng, W., Spinks, G. M., and Wallace, G. G. (2016). "Organic Conducting Polymer Actuators," in The WSPC Reference on Organic Electronics: ORGANIC SEMICONDUCTORS, 2: Fundamental Aspects of Materials and Applications. Editors J. L. Bredas and S. R. Marder (Singapore: World Scientific), 321-343. doi:10.1142/9789813148611_0010

Zotti, G., Schiavon, G., Berlin, A., and Pagani, G. (1993). Thiophene Oligomers as Polythiophene Models 3. Conductive and Capacitive Behavior of End-Capped Oligothienyls as Thin Films. A Contribution to the Conduction Mechanism and to the Faradaic-Capacitive Debate of Conducting Polymers. Adv. Mater. 5, 551-554. doi:10.1002/adma.19930050706
Zotti, G., and Schiavon, G. (1994). Electrochemical N-Doping of Poly(dithienylvinylene). A Comparison of Cyclovoltammetric and Conductive Properties in N- and P-Doping. Synth. Met. 63, 53-56. doi:10.1016/0379-6779(94)90248-8

Zotti, G., and Schiavon, G. (1989). The Polythiophene Puzzle. Electrochemical and Spectroelectrochemical Evidence for Two Oxidation Levels. Synth. Met. 31, 347-357. doi:10.1016/0379-6779(89)90802-3

Zotti, G., Schiavon, G., and Zecchin, S. (1995). Irreversible Processes in the Electrochemical Reduction of Polythiophenes. Chemical Modifications of the Polymer and Charge-Trapping Phenomena. Synth. Met. 72, 275-281. doi:10.1016/0379-6779(95)03280-0

Conflict of Interest: The authors declare that the research was conducted in the absence of any commercial or financial relationships that could be construed as a potential conflict of interest.

Publisher's Note: All claims expressed in this article are solely those of the authors and do not necessarily represent those of their affiliated organizations, or those of the publisher, the editors, and the reviewers. Any product that may be evaluated in this article, or claim that may be made by its manufacturer, is not guaranteed or endorsed by the publisher.

Copyright (c) 2021 Dini, Salatelli and Decker. This is an open-access article distributed under the terms of the Creative Commons Attribution License (CC $B Y)$. The use, distribution or reproduction in other forums is permitted, provided the original author(s) and the copyright owner(s) are credited and that the original publication in this journal is cited, in accordance with accepted academic practice. No use, distribution or reproduction is permitted which does not comply with these terms. 